\title{
Pandemia e Política
}

\author{
Pandemic and Politics
}

\author{
Maria Elisabete Pereira dos Santos ${ }^{1}$ \\ Renata Alvarez Rossi ${ }^{2}$
}

\section{RESUMO}

Este texto passeia por alguns dilemas da nossa política em tempos de pandemia. Recorre a Albert Camus e a pensadores clássicos no campo do liberalismo, como Bernard Mandeville, Adam Smith e Friedrich Hayek, para discutir o significado, em tempos idos e nos dias de hoje, da exacerbação da tese da liberdade individual, em contextos de crise sanitária. Hannah Arendt, Richard Sennett e Wilhelm Reich, com Zé Ninguém, ajuda-nos a refletir sobre a complexa associação entre pandemia, autoritarismo e neofascismo. O texto recorre ainda a Lilia Schwarcz e a Jessé de Souza, com o objetivo de explicitar as raízes escravistas e autoritárias da sociedade brasileira. A discussão estrutura-se a partir da recorrência a textos dos referidos autores e conclui pela necessidade, no atual contexto de esquecimento da política, ataque à democracia liberal burguesa e hegemonia de forças políticas de extrema direita, nestes tempos de Zé Ninguém, de reinventar a esfera pública, a politica e o futuro.

Palavras chave: Pandemia; Politica; Crise.

\begin{abstract}
This paper goes by some dilemmas of our politics in times of pandemic. It refers to Albert Camus and classic thinkers in the field of liberalism, like Bernard Mandeville, Adam Smith and Friedrich Hayek, to discuss the meaning, in olden times and nowadays, of the exacerbation of the thesis of individual freedom, in contexts of sanitary crisis. Hannah Arendt, Richard Sennett and Wilhelm Reich, together with a nobody, help us reflect about the complex association between pandemic, authoritarianism and neofascism. This paper also refers to Lilia Schwarcz and Jessé de Souza, aiming at making explicit the enslavement and authoritarian roots of Brazilian Society. The discussion is based on the reference to texts of the aforementioned authors and concludes by the need, in the current context of oblivion to politics, attack on bourgeois liberal democracy and hegemony of extreme right political forces, at these times of a nobody, to reinvent the public sphere, politics and the future.
\end{abstract}

Keywords: Pandemic; Politics; Crisis.

\footnotetext{
1 Doutora em Ciências Sociais, pesquisadora do Grupo AGUAS/CNPQ e professora da Escola de Administração da Universidade Federal da Bahia. E-mail: betesantos@ufba.br.

${ }^{2}$ Doutora em Administração, pesquisadora do Grupo AGUAS/CNPQ e professora da Escola de Administração da Universidade Federal da Bahia. E-mail: renatarossi@ufba.br.
}

Artigo Convidado para compor este Fórum Especial em Democracia, Políticas Públicas e COVID-19. Agradecemos às autoras a participação neste debate tão urgente. 
1. Em plena década de quarenta do século passado, mais precisamente em 1947, Albert Camus, dentre várias outras ocupações, professor primário, argelino-francês e filho de um operário, presenteia-nos com o clássico A Peste. Nesse tempo, ainda com resquício colonial, quando a ocupação nazista assola a França e a Europa, no imaginário de Camus, a peste bubônica devasta uma cidade no litoral mediterrâneo da Argélia, Oran. A Peste é um exemplo da desconcertante vertigem vivida por quem se aproximou dos limites da vida e conviveu com a morte e uma metáfora, contundente, dos horrores produzidos pelo nazifascismo na Europa. A associação entre peste e fascismo, na primeira metade do século passado e pandemia e neofascismo (ou termos equivalentes), nos dias de hoje, particularmente no Brasil, torna essa obra estranhamente atual.

Camus apresenta-nos Oran de um modo sedutor. Começa com a observação de que um modo de você conhecer um lugar é saber como se trabalha, se ama e se morre: "une manière commode de faire la connaissance d'une ville est de chercher comment on y travaille, comment on y aime et comment on y meurt." (CAMUS, 1972, p.11). Oran é uma cidade amarela e cinzenta, sem vegetação e sem alma, onde as pessoas trabalham, principalmente, no comércio, ocupam-se em fazer negócios. Eles reservam os prazeres para os dias de sábado à noite a aos domingos e, nos outros dias, procuram ganhar dinheiro, "gagner beaucoup d'argent' (CAMUS, 1972, p.12). Mas, afinal, nós, modernos, não somos todos assim? Sim, afirma Camus. Porém, tem lugar no qual as pessoas suspeitam que existe "algo a mais" a conferir significado à vida: "il est des villes et des pays où les gens ont, de temps en temps, le soupçon d'autre chose". Essa suspeita pode não modificar a própria vida mas a sua existência, já significa algo. Oran é uma cidade sem suspeitas. E por isso não se tem muito a falar de como as pessoas se amam - ou se devoram. O que, de fato, é singular na cidade é como as pessoas morrem. Do desconforto, da solidão da morte, nessa cidade "un malade s'y trouve bien seul" (CAMUS, 1972, p.13). Nesse tempo, em Oran, assim como na França e na Europa, a morte invade a tudo e a todos.

Lá e aqui, em tempos idos e nos dias de hoje, quem vela por nós, em tempos de pandemia e de recusa da política? O amigo, a família, a ciência, a técnica, a política, o estado, a política pública, as organizações e instituições sociais, esse ente, genérico, concreto-abstrato que é a sociedade, as organizações transnacionais? Se puder, fique em casa! Quem é (são) o(s) sujeito(s) dessa fala e a quem ela se dirige? Quem "pode" ficar em casa e quem "não pode" parar? Como a política, no Brasil, lida com a pandemia?

2. Aqui e agora, quem vela por nós, segundo formulações de representantes de forças políticas que estão à frente da gestão estatal na esfera federal, é o imponderável, o laissez faire. É quase que um "salve-se quem puder", ou seja, é cada um por si e Deus por todos - salvar-se-ão os mais fortes, resilientes, os mais aptos ou com capacidade de adaptação, aos novos tempos. O que tem sido feito da política ou em nome da política, em seu sentido lato, quando o tecido social se esgarça e os recursos públicos são ditos como escassos e a economia não pode parar? No confronto entre pandemia e politica, a política se amesquinhou. Encontramos exposto, de forma sangrenta, o princípio de que o que qualificamos como sociedade não é nada mais do que o resultado de múltiplas, incontáveis, interações, fruto da fruição, nem sempre democrática, de interesses individuais e privados. Vivemos hoje, de forma dramática, o princípio de que é o interesse individual que, ao realizar-se, produz o interesse coletivo. Se for possível! Caso contrário... Que sobreviva o mais apto. É como se o velho liberalismo estivesse sendo superado por ele mesmo - em sua versão mais perversa, oferecendo-se como lastro para expressão do ódio e como justificativa para a aniquilação do outro.

Mas, afinal, onde foi parar a tese, clássica, de que a realização do interesse privado tornaria possível o interesse coletivo? De que a sociedade, ao cuidar de cada um, cuidaria de todos, ainda que em condições diferenciadas? Voltemos a essa concepção recorrendo a Friedrich Hayek, ou seja, a uma versão mais próxima da concepção liberal da política e de democracia (e que se diferencia, inclusive, do que Yascha Mounk (2019) chama, por exemplo, de democracia iliberal). 
3. Segundo Hayek, quem vela por nós, ontem, hoje, e sempre é ação individual que, no contexto das incontáveis e imponderáveis interações, produz a regra, a tradição, enfim, a civilização. O que nos torna humanos é o fato de que nós produzimos e aprendemos com a regra. Não é o instinto. Não é a razão. É a produção da regra que constitui a civilização e ela é fruto, resultado, da complexa relação entre "instinto e a razão" (HAYEK, 2017, p.21). A civilização não é nada além do que a produção e o aprendizado da regra. "O homem alcançou a civilização desenvolvendo e aprendendo a seguir (...) regras que muitas vezes o proibiam de fazer o que seus instintos exigiam e que já não dependiam da percepção comum dos acontecimentos." (HAYEK, 2017, p.21). A regra não é fruto do instinto ou de uma razão transcendente (de origem divina ou coletiva), ela é filha da "tradição, do ensino, e da imitação", que se convertem em hábito: "reflexos inatos não têm qualidade moral" (HAYEK, 2017, p.21). E a moralidade emana da regra.

O homem faz-se homem através da tradição, que permite o aprendizado. Movemo-nos, permanentemente, entre o instinto e a razão - locus onde a regra é produzida. Em síntese, "foram a moralidade e a tradição, e não a inteligência e o cálculo racional, que elevaram o homem acima dos selvagens (...)" e é a "evolução espontânea das regras de conduta que acompanha a formação de estruturas auto organizáveis", o que torna a interferência "racional" em uma ordem espontânea um risco ao próprio homem (HAYEK, 2017, págs.42, 52). O Estado, então, precisa e deve ser mínimo, a força, a vontade da maioria não pode converter-se em uma tirania e ameaçar o bem maior que é a liberdade individual.

Recorrendo a Bernard Mandeville (2018), à Fabula das Abelhas, Hayek lembra-nos que até mesmo o mal nos torna criaturas sociais, ou seja, os vícios privados podem se converter, sim, em virtudes públicas. $\mathrm{Na}$ velha Inglaterra do século XVII, Mandeville afirma que o homem não tende, necessariamente, à virtude, a deixar-se governar pela razão: "(...) orgulho-me em ter demonstrado que os fundamentos da sociedade não são as qualidades amigas e as afeições delicadas que são naturais ao homem, nem as virtudes reais que 0 homem é capaz de adquirir pela razão e pela abnegação (...)" (MANDEVILLE, 2018, p.2). O vício, a luxúria, a ganância e a inveja nos tornam humanos e sociáveis, produzem o bem comum. Esse é o esteio da vida e o dia em que os predicados e o interesse próprio deixarem de se constituir no motor da vida a sociedade estará em ruína:

Assim, o vício em cada parte vivia, Mas o todo, um paraíso constituía; Temidos na guerra, na paz incensados,

Pelos estrangeiros eram respeitados,

$\mathrm{E}$, de riquezas e vidas abundante, Entre as colmeias era a preponderante. (...)

O pior elemento em toda a multidão realizava algo para o bem da nação. (...)

Mas Júpiter, de indignação tomado

E, por fim, irritado, jurou de vez Livrar a colmeia da fraude. E assim fez.

Vede agora na colmeia renomada Honestidade e negócios de mão dada;

O show terminou; foi-se rapidamente,

E mostrou-se tom, face bem diferente.(...) Enquanto que orgulho e luxo minguavam,

Gradativamente os mares deixavam, 
Não os mercadores, mas companhias. Fábricas fechavam todos os dias. Artes e ofícios mortos estão. (...)

Triunfaram, porém não sem azares, Pois as abelhas morreram aos milhares.

(MANDEVILLE, 2018)

Mas, a despeito do embate entre vícios e virtudes, Adam Smith nos lembra que, decisivamente, "não é da benevolência do açougueiro, do fabricante de cerveja ou do padeiro que esperamos nosso jantar (...)" (SMITH, 1996, p.74). É do interesse próprio, da vantagem do açougueiro e do cervejeiro que depende o meu provimento. Em uma sociedade assim, qualquer restrição à liberdade individual é uma ameaça à própria sociedade. A racionalidade é aqui um atributo, o resultado das ações individuais e privadas, que não deve e não pode ser controlada, sem que traga grande prejuízo à própria sociedade.

Em uma sociedade estruturada com base em tais princípios, a responsabilidade por prover as condições de subsistência e sobrevivência é do próprio indivíduo. O Estado, aqui, é concebido como ente cuja função é propiciar o desenvolvimento, pleno do mercado (que, afinal, é anterior ao próprio estado), por meio da garantia da propriedade privada e dos direitos a ela associados. Cabe ao estado criar as condições materiais e simbólicas para que a livre iniciativa floresça, garantir a propriedade e defender o indivíduo contra a injustiça e a opressão (SMITH, 1996). Nesse exato sentido, o planejamento, a intervenção estatal para além do preconizado pelo princípio liberal, é uma ameaça à própria sociedade - à liberdade. Como ressalta Jürgen Habermas, a esfera pública burguesa é, assim, o resultado da adição dos distintos interesses privados (HABERMAS, 1984). Nesse exato sentido, o estado, na sociedade burguesa, ainda que se apresente como resultado de um pacto social, é uma organização de proprietários.

Como bem assinala Hanna Arendt (2010), ao transformar o "interesse privado pela propriedade privada em uma preocupação pública", o estado torna-se uma "organização de proprietários [property-owners] que, ao invés de requererem o acesso ao domínio público em virtude de sua riqueza, exigem dele proteção para o acúmulo de mais riqueza." (ARENDT, 2010, p.83). O estado seria, então, um "corpo de povos e comunidades políticas, como uma grande família, cujos assuntos diários deveriam ser zelados por uma gigantesca administração doméstica no âmbito nacional", sob comando de um chefe, um senhor, que expressa e defende uma única opinião, um único interesse (ARENDT, 2010, p.34).

No Brasil dos tempos atuais, essa constatação, aparentemente exagerada, torna-se uma literal e perturbadora realidade. Ainda que estejamos em contextos de disputa entre os vários interesses, estamos enredados em vontades e interesses privados - em um cenário de exacerbação do que Hayek, Smith e Mandeville definem como sendo a natureza da nossa sociabilidade, ou seja, a liberdade individual, de onde emana a política. Em tempos de pandemia, essa concepção resulta em uma política pública que tem como marco o contraponto entre vida e economia. Na afirmação da inevitabilidade da morte (um dia, todos morreremos!) e na defesa da economia - afinal, o país não pode parar. E a política como a arte de lidar com $o$ interesse coletivo se esvai.

4. Existem alternativas à referida concepção de sociedade, em tempos de pandemia? O contraponto a essa concepção liberal, dentro dos marcos do próprio capitalismo, tem sido apresentado por concepções de inspiração keynesiana, para as quais o estado pode e deve atenuar os efeitos das crises, da desigualdade e da exclusão social. Nos seus próprios termos, John Maynard Keynes afirma: "(...) em condições de 'laissez-faire', talvez seja impossível evitar grandes flutuações no emprego sem uma profunda mudança na psicologia do mercado de investimentos, mudança essa que não há razão para esperar que ocorra. Em 
conclusão, acho que não se pode, com segurança, abandonar à iniciativa privada o cuidado de regular o volume corrente de investimento." (KEYNES, 1982, p. 247-248). Em benefício desse princípio têm-se as mais variadas experiências de construção de welfare state nas últimas décadas em vários cantos do mundo. No atual contexto de assombro diante dos efeitos pandemia, e pressionados pelo embate em torno da tese do isolamento social, forças políticas situadas no espectro neoliberal tem aderido ao campo do keynesianismo colocando em destaque a necessidade de preservação da vida. No Brasil, o ex-ministro da saúde, com estreita vinculação à planos de saúde privados, assumiu a defesa do isolamento social e do Sistema Único de Saúde, ou seja, do estado como sistema de proteção social (embora não tenha conseguido sustentar essa posição por muito tempo).

Em tempos de crise, é muito comum encontrarmos liberais defendendo a intervenção do estado. O que está em jogo, no entanto, é a natureza e o objetivo da intervenção, se salvar mercados ou, em neste caso, salvar vidas. O ex-ministro da Fazenda Mailson da Nóbrega, dentre outros economistas de formação e inspiração liberal, têm defendido uma maior atuação do estado no enfrentamento da atual crise da pandemia. $O$ exministro, por exemplo, defende a injeção de mais dinheiro público na economia do país e nos lembra que: proposta semelhante foi feita por Milton Friedman, um dos expoentes da Escola de Chicago, ferrenho opositor da intervenção do Estado na economia. Ele propôs que, em certos momentos, seria mais eficaz distribuir dinheiro de helicóptero do que confiar na ação do governo para estimular a demanda. As pessoas que apanhassem as notas as utilizariam para consumir. (NOBREGA, 2020) (grifo nosso).

Assim, ainda que estejamos falando da ação do estado para a remediação dos efeitos nocivos da pandemia, podemos estar diante, tão somente, de concepções que entendem que, para a manutenção do sistema, o estado deve atuar como uma super firma, aproveitando-se de sua condição de gestor para atuar sobre "externalidades negativas" produzidas pelo próprio sistema e, ao mesmo tempo, minimizar os custos de operação das firmas - como mostram o trabalho dos expoentes da chamada Nova Economia Institucional, a exemplo de Ronald Coase (1937; 1960) e Oliver Williamson (1993). Não se trata, portanto, de questionar os fundamentos privados e mais ou menos democráticos da ação estatal e, desse modo, podemos estar diante de um embate mais complicado do que o enunciado pelo dilema entre vida e economia e o estado. Afinal, o estado liberal, teria, sim, a tarefa de arcar com o ônus da crise de modo que não estamos exatamente diante de um welfare state mas de um estado liberal que, como afirma a própria Hanna Arendt, é uma organização de proprietários - que precisa defender-se em tempos de crise.

Assim, muito do que vemos como proposta de ação governamental para enfrentamento da crise supõe, como remédio ou solução para as desigualdades potencializadas pela situação de pandemia, a reafirmação do sistema de mercado (em doses diferenciadas) como lócus de produção e alocação de recursos - o que consideramos como um dos fundamentos da crise atual. Como afirma Boaventura Santos (2020), em recente texto, "a pandemia vem penas agravar uma situação de crise a que a população mundial tem vindo a ser sujeita. Daí a sua específica periculosidade. Em muitos países, os serviços públicos de saúde estavam mais bem preparados para enfrentar a pandemia há dez ou vinte anos do que estão hoje." (SANTOS, 2020, p.6).

Não podemos também deixar de lembrar que a característica fundamental do chamado welfare state, com a construção de um forte sistema de previdência social, proteção do trabalho e também à reprodução ampliada do capital - teve como fundamento a concertação entre classes sociais (e frações de classe), amenizando conflitos em favor da reprodução do capitalismo. Neste modelo, recorrendo aqui a Nelson Oliveira (1999), a tese de equilíbrio do sistema é um dos pressupostos e requisitos para o lucro. Já sob as condições estabelecidas pelo modelo neoliberal, "continua-se a defender a harmonia, mas esta deixa de ser pressuposto para se transformar numa consequência do lucro. É a queda deste que passa a constituir numa ameaça àquela, não a ausência de sua regulação, como supunha ser a visão socialdemocrata dominante." (OLIVEIRA, 1999, p. 137). Serão, portanto, consistentes as propostas que se aproximam do modelo 
keynesiano, em um contexto político e institucional de profundo acirramento das contradições de classes?

Estruturalmente e, retornando a Arendt (2010), independente das versões mais ou menos liberais, estamos diante de um estado moldado e capturado por interesses privados, o que evidencia o seu caráter de classe. A alternância entre modelos mais ou menos inclusivos, funcionalmente, termina por se constituir em distintas estratégias que resultam na reprodução da acumulação em uma escala globalizada, o que condiciona a política e as suas distintas formas de organização e manifestação.

5. Esse cenário de crise, de falta de perspectiva, tem resultado no amesquinhamento, no esquecimento ou negação da política. A recomendação de isolamento social, que nos protege diante da falta de uma terapia e do possível colapso do sistema de saúde, faz com que nos recolhamos ao espaço privado. A vida no espaço público, no partido, sindicato, na reunião de departamento na nossa instituição de ensino, na reunião do condomínio ou mesmo o encontro no shopping, na praça pública, no campo de futebol nos torna senhor de um lugar, de um tempo, de um conjunto de relações. A vida na rede é efêmera, errática. E ela potencializa a inserção e manifestação, sobretudo, individual e o faz diluindo a fronteira entre o público e o privado.

O recolhimento ao espaço privado como forma de proteção sanitária reforça a percepção do espaço público como ameaça: "saia da rua, vá pra casa". Nesse contexto, as tensões entre o público e o privado se acirram sendo que, como lembra Gilberto Dupas (2003), a negação do espaço público é a negação da própria democracia, pois é no espaço público onde ocorre a explicitação das ideias e no qual ocorre a "mediação pela sociedade política" (DUPAS, 2003, p.18).

A negação do espaço público como possibilidade de construção de alternativas politicas é um elemento constitutivo da sociedade brasileira. Aliás, melhor dizendo, o espaço público possível no país sempre se caracterizou pela recusa da dimensão propriamente coletiva da política - a começar pela negação dos conflitos que perpassam as relações sociais: a falaciosa tradição de que vivemos em harmonia, que somos, naturalmente, propensos à informalidade, o "jeitinho brasileiro", como forma de resolver nossos problemas cotidianos. Criamos o mito da uma sociedade solidária, de uma democracia, na qual não teria lugar a desigualdade, como as de raça e de gênero, enfim, de renda. (SCHWARCZ, 2019). Enquanto essa tradição molda nosso imaginário social, em verdade, mantemos inalteradas estruturas que produzem desigualdades históricas e profundas.

Afinal, como falar em democracia em um país que ainda não superou as desigualdades produzidas pela escravidão, que tem por marca elevados índices de feminicídio e os menores números de mulheres em espaços de poder e decisão, e que renova o rol de vítimas das desigualdades e intolerâncias contra população LGBTQI+, religiões, posições políticas? Como falar em democracia em um país que escreve a história apagando e negando o caráter violento e autoritário da recente experiência do regime militar - como o fazia Winston Smith, o funcionário do Ministério da Verdade no distópico 1984, de George Orwell, responsável por reescrever a história, transformando o Grande Irmão, de figura totalitária e opressora, em grande conquistador e redentor da humanidade?

Aqui, como alertou Sennett (2009), a negação do conflito converte-se em "uma tentativa de se resolver o problema público negando que o problema público exista, [e] como acontece com toda negação, isso só serv[e] para entrincheirar, mais firmemente, os aspectos mais destrutivos do passado." (SENNETT, 2009, p.44). Negar o conflito, hoje e sempre, é uma forma de manter tudo como está.

Lilia Schwarcz (2019), ao falar sobre o autoritarismo brasileiro, relembra Frei Vicente do Salvador que, em 1630, afirmava que "nenhum homem nesta terra é repúblico, nem zela, ou trata o bem comum, senão cada um do bem particular", com o agravante de que os bens particulares referiam-se à posse de grandes porções de terra tornadas improdutivas (os latifúndios) e à posse sobre outras pessoas que trabalhavam (escravizadas) (SCHWARCZ, 2019, p. 41). A casa grande, a figura do senhor de terras forjou uma sociedade 
patriarcal, estratificada, elitista, privatista, que desvaloriza o trabalho (SOUZA, 2019). As estruturas de mandonismo local, os "currais eleitorais", os "votos de cabrestos" forjaram a "figura mítica do pai político agora uma espécie de chefe virtual, que fala em nome e no lugar dos filhos e descendentes -, do herói destacado e excepcional, do líder idealizado." (SCHWARCZ, 2019, p.63). Assim, as conquistas recentes no campo de direitos sociais e ampliação do acesso a políticas públicas, experimentadas no Brasil nos anos 2000, convivem com uma estrutura - ou se quisermos, com uma tradição - que concentra riquezas e poderes e que ameaça, portanto, avanços mais significativos para uma democracia mais inclusiva.

6. No cenário anteriormente descrito, em escala maior ou menor, o único lugar seguro é a casa e cabe, a cada um, prover as condições de sobrevivência, sem colocar em risco a lógica do sistema. Imagine o significado do retorno ao espaço privado para parcela significativa da população que não tem casa, que tem arremedos de casa e que não tem um sistema de proteção que torne possível parar de trabalhar e "trancarse em casa".

O fato é que, se tem sido dito que é por meio da manutenção do pleno funcionamento do sistema que encontraremos a saída para nossa agonia. As tentativas (e ameaças, em alguns, casos como em relação às instituições de ensino) de flexibilização das medidas de isolamento, as carreatas elitizadas em nome do retorno à "normalidade" das atividades comerciais reverberam, de forma perversa, essa determinação, que se converte em politica pública. Afinal, o quanto a pandemia exacerba a dimensões privada, individualista, da vida e da política?

É preciso lembrar que o retorno a um modelo neoliberal, em uma versão radicalizada, vem acompanhado de uma negação sistemática aos princípios da democracia liberal clássica. Vivemos, hoje, a crise e dissolução de formas tradicionais de representação e o que aparece de forma violenta e desconcertante são manifestações qualificadas como de direita, melhor dizendo, de extrema direita. Debatemo-nos tentando dar nomes e qualificar esse tempo de pandemia e de autoritarismo e nos perdemos e nos encontramos em torno do que, genericamente, qualificamos como fascismo ou neofascismo ou seja, da recusa extremada da política.

O que separa e aproxima a recente experiência de ditadura vivida pela América Latina e pelo Brasil do que experimentamos nos tempos de hoje? E mesmo, voltado a Oran, como se associaram a peste e fascismo? A chegada ao poder dos militares em 1964 foi através da força. O nazi-fascismo na Europa e o atual governo chegaram ao poder através de escolha popular. O governo atual é legitimo, no exato sentido que representa um conjunto amplo de forças econômicas, sociais e políticas - o fascismo também teve a sua necessária dose de legitimidade.

7. Ainda que estejamos assistimos manifestações cotidianas de pedido de retorno à ditadura militar, agora, com Bolsonaro na liderança, como afirmam muitos dos representantes de instituições as mais distintas: vivemos em uma democracia, as instituições estão em pleno funcionamento. Sem entrar aqui no mérito do debate sobre conceitos e práticas qualificadas como democráticas, o fato é que temos hoje no cenário nacional, nas esferas de poder, forças políticas que negam sistematicamente princípios os mais fundamentais da democracia liberal burguesa - muitos são os exemplos mundo a fora, de governos qualificados como de extrema direita.

Nesse cenário de crise de representação e de hegemonia, ainda que débil, de forças políticas de extrema direita a noção de uma representação coletiva, com um caráter político mais radical se esvai. A chamada esquerda, hoje, se fragmenta e, atônita, se debate, sem uma estratégia política bem definida. O que temos, de forma clara no cenário político nacional, é a afirmação, no campo da extrema direita, de uma liderança trôpega, de caráter messiânico, que recusa a mediação institucional, que desdenha das instituições e formas 
de representação instituídas (das quais é fruto), personalista, com forte caráter de irracionalidade e moralismo retrógrado, autoritário e que conjuga um certo elitismo com um populismo seletivo.

É possível chamar a isso de neofascismo? Poderíamos talvez, recorrendo a Wilheim Reich (2007), em Escute Zé Ninguém, compreender melhor como uma tal personalidade ou como tais traços de personalidades se convertem em alternativa de poder nos tempos de hoje. Talvez possamos afirmar que, pela primeira vez, temos na presidência da república a expressão bem acabada de um Zé Ninguém. É difícil, mas, também, é fácil compreender o Zé Ninguém. É difícil, por conta da complexidade da personalidade assim nomeada. É fácil, pois cada um de nós tem dentro de si um Zé Ninguém. Falar dessa personagem significa falar, simultaneamente, do outro e de nós mesmos.

Esse nome e sobrenome não são a expressão ou representação da identidade de um homem do "povo". É fácil reconhecê-lo, sobretudo quando o vemos nu: "nu como um recém-nascido; nu como um marechal de cuecas." (REICH, 2007, p. 10). O que faz de qualquer um de nós, no cotidiano, em tempos de pandemia e de neofascismo um Zé Ninguém? É a incapacidade de nos reconhecermos como sujeitos da própria vida. É a situação inusitada de não ter opinião e, ainda assim, fazer parte da "opinião pública"; de abaixar a cabeça e reverenciar nossos superiores e inimigos e desprezar e maltratar nossos amigos. De, na condição de poder, reproduzir as relações de subordinação as quais estávamos submetidos. Zé Ninguém, afirma Reich, "esconde sua insignificância e estreiteza por trás de ilusões de força e de grandeza, da força e grandeza de alguma outra pessoa. Sente orgulho dos seus grandes generais, mas não de si mesmo. Admira uma ideia que não teve, não uma ideia que teve. Quanto menos entende uma coisa, mais firme é a sua crença nela. E quanto melhor entende uma ideia, menos acreditará nela." (REICH, 2007, p. 11).

Afinal de contas, no atual contexto de esquecimento da política, de ataque a democracia liberal burguesa, de hegemonia de forças políticas de extrema direita, de tempos de Zé Ninguém, as forças políticas consideradas como progressistas e democráticas (em um sentido mais radical e substantivo) precisam reinventar o futuro. É preciso retomar o interrompido processo de construção de esferas públicas inclusivas, distintas da esfera pública tradicional, liberal, burguesa que tem no indivíduo seu fundamento primeiro como bem diz Marilena Chauí (2013), a esfera pública como lugar, como expressão das vontades coletivas e não como imposição de vontades privadas ou de um soberano.

8. Seremos, enfim, capazes de recuperar o espaço público como domínio no qual os sujeitos interagem e se reconhecem, onde poderão produzir alternativas efetivamente solidárias e democráticas? Conta a lenda, no facebook (que pecado!), que Margaret Mead, certa feita, foi questionada por uma aluna, sobre os sinais do que teria nos tornado uma civilização e sua resposta foi singela: um fêmur quebrado e curado. No mundo animal se você quebrar uma perna você morre. É o cuidado com o outro que funda a nossa humanidade. A pandemia, quem sabe, pode nos ajudar a reinventar a própria noção de sociedade, consequentemente a política - política como a arte de lidar com o coletivo, de reconhecer e mediar conflitos, do cuidado com o outro. Voltemos à Camus, à Oran, que nos lembra que os flagelos são comum, que o mundo já viveu tantas pestes quantas guerras, e que o problema, na verdade, é que estamos sempre desprevenidos: "Les fléaux, en effet, sont une chose commune, mais on croit difficilement aux fléaux lorsqu'ils vous tombent sur la tête. Il y a eu dans le monde autant de pestes que de guerres. Et pourtant pestes et guerres trouvent les gens toujours aussi dépourvus" (CAMUS, 1972, p.41). Precisamos nos reinventar, proteger e prevenir, contra a pandemia e contra o neofascismo. Para que a gente possa viver e morrer sem medo e sem sentir solidão, como em Oran.

\section{Referências}

ARENDT, Hannah. A condição Humana. Rio de Janeiro: Forense Universitária, 2010.

CAMUS, Albert. La peste. Paris: Gallimard, 1972. 
CHAUÍ, Marilena. Contra a Servidão Voluntária. Belo Horizonte: Autêntica Editora; São Paulo: Fundação Perseu Abramo, 2013.

COASE, Ronald. The Nature of the Firm. Economica, New Series, v. 4, n. 16, n. 1937.

The Problem of Social Cost. The Journal of Law \& Economics, v. III, 1960.

DUPAS, Gilberto. Tensões Contemporâneas entre o Público e o Privado. São Paulo: Editora Paz e Terra, 2003.

HABERMAS, Jürgen. Mudança Estrutural da Esfera Pública. São Paulo: Tempo Presente, 1984.

HAYEK, Friedrich. O Caminho para a Servidão. Portugal: Edições 70, 2009.

HAYEK, Friedrich. Os Erros Fatais do Socialismo. Barueri: Faro Editorial, 2017.

KEYNES, J M. Teoria Geral do Emprego, do Juro e da Moeda. São Paulo: Atlas, 1982.

MANDEVILLE, Bernard. A fábula das abelhas: ou Vícios Privados, Benefícios Públicos. São Paulo: Editora Unesp, 2018.

MOUNK, Yascha. O povo contra a democracia: Porque nossa liberdade corre perigo e como salvá-la. São Paulo: Companhia das Letras, 2019.

NOBREGA, Mailson da. Imprimir dinheiro pode ser uma medida eficaz na Crise. Disponível em: $<$ http://mailsondanobrega.com.br/blog/imprimir-dinheiro-pode-ser-uma-medida-eficaz-na-crise/>. Acesso em 10 de abril de 2020.

ORWELL, George. 1984. São Paulo: Companhia das Letras, 2019.

OLIVEIRA, Nelson de. Neocorporatismo e Estado: A Construção do Espaço de Dominação Setorial. Revista O\&S, Salvador, v.6, n. 15, mai./ago., 1999.

REICH, Wilhelm. Escute, Zé-Ninguém. São Paulo: Martins Fontes, 2007.

SMITH, Adam. A Riqueza das Nações: Investigação sobre sua natureza e suas causas. São Paulo: Editora Nova Cultural, 1996.

SANTOS, Boaventura de Souza. A Cruel Pedagogia do Vírus. Coimbra: Edições Almedina, 2020.

SCHWARCZ, Lilia. Sobre o Autoritarismo Brasileiro. São Paulo: Companhia das Letras, 2019.

SENNETT, Richard. O Declínio do Homem Público: as tiranias da intimidade. São Paulo: Companhia das Letras, 1999.

SOUZA, Jessé. A Elite do Atraso. Rio de Janeiro: Edição Brasil, 2019.

WILLIAMSON, Oliver. Transaction Cost Economics and Organization Theory. Journal of Industrial and Corporate Change, n.2, p. 107-156, 1993. 